
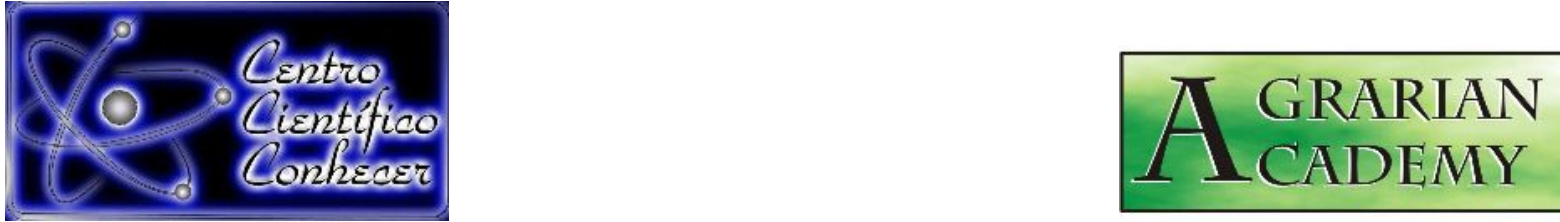

\title{
GERENCIAMENTO DOS RESÍDUOS SÓLIDOS DA INDÚSTRIA DE BASE FLORESTAL NA REGIÃO METROPOLITANA DE BELÉM-PA
}

Wilson Fernandes Ramos ${ }^{1}$, Maria de Lourdes Pinheiro Ruivo ${ }^{2}$, Larissa Melo de

Sousa $^{3}$, Uêbem Fernandes Ramos ${ }^{4}$, Rosecélia Moreira da Silva Castro ${ }^{5}$

1. Doutorando em Ciências Ambientais, Universidade Federal do Pará/UFPA, Belém, PA, Brasil. (wilson.f.ramos18@hotmail.com)

2. Pesquisadora Titular. Museu Paraense Emilio Goedi/MCTI, Belém (PA),

Bolsista CNPQ.

3. Doutoranda em Ciências florestais, Universidade Federal Rural da

Amazônia/Ufra, Belém, PA, Brasil.

4. Mestrando em Ciências Farmacêuticas, Universidade Federal do Pará/UFPA, Belém.

5. Bolsista Pós-Doutorado da Coordenação de Aperfeiçoamento de Pessoal de Nível Superior

(CAPES) pela UFPA

Recebido em: 14/07/2018 - Aprovado em: 28/07/2018 - Publicado em: 31/07/2018

DOI: 10.18677/Agrarian_Academy_2018a35

\section{RESUMO}

A indústria de base florestal apresenta grande relevância no contexto econômico, pois seus produtos são usados como matéria-prima para outros setores da industrial. Assim, objetivou-se descrever o gerenciamento dos resíduos sólidos da indústria de base florestal na Região Metropolitana de Belém. Do ponto de vista metodológico, o presente trabalho se classifica como um estudo descritivo, observacional, aplicado e tem caráter de pesquisa exploratória. Os dados foram coletados através da entrevista semi-estruturada, além disso, visitas in loco e registro fotográfico da área de disposição, armazenamento e gerenciamento de resíduos foram feitas. Os resultados mostraram que os resíduos das empresas são destinados de três formas, quais sejam: doação, venda e logística reversa interna. Os resíduos são vendidos para outras empresas do setor madeireiro, para cerâmicas, olarias e granjas. Já a doação os resíduos são destinados basicamente para panificadoras, granjas, comunidade, olarias e cerâmicas, nenhuma empresa doa para mais de um local. $\mathrm{Na}$ logística reversa interna, os resíduos são aproveitados através do processo de reciclagem para a fabricação de briquete, pequenos objetos de madeira (POM), os quais são vendidos como subprodutos do processo produtivo, também são utilizados em caldeiras ou fornos para a geração de energia térmica ou elétrica (co-geração de energia). Conclui-se que os resíduos são destinados de diversas formas, algumas com grau de aceitabilidade ambiental, outras não. Das diversas formas de destinação a logística reversa é a que gera ganhos econômicos a empresa.

PALAVRAS-CHAVE: Gerenciamento de Resíduo. Indústria florestal. Resíduos de madeira.

\section{MANAGEMENT OF SOLID WASTE FROM THE FORESTRY INDUSTRY IN THE METROPOLITAN REGION OF BELÉM-PA ABSTRACT}

The forestry industry together with the mineral industry is the basis of the world economy, since its products are used as raw material for other economic sectors. The AGRARIAN ACADEMY, Centro Científico Conhecer - Goiânia, v.5, n.9; p. 3582018 
objective of this study was to describe the management of solid waste from the forest-based industry in the Metropolitan Region of Belém. From the methodological point of view, the present work is classified as a descriptive, observational, applied and exploratory study. The data were collected through the semi-structured interview, in addition, on-site visits and photographic records of the disposal, storage and waste management area were made. The results show that the companies' waste is destined in three ways: donation, sale and internal reverse logistics. The waste is sold to other companies in the timber sector, for ceramics, potteries and farms. Already the donation of the waste is destined basically for bakeries, farms, community, potteries and ceramics, no company donates to more than one place. In internal reverse logistics, waste is used through the recycling process for the manufacture of briquettes, small wooden objects (POM), which are sold as byproducts of the production process, are also used in boilers or ovens for the generation of energy thermal or electric (co-generation of energy). It is concluded that the waste is destined in several ways, some with environmental degree of acceptability, others not. Of the various forms of destination the reverse logistics is the one that generates economic gains to the company.

KEYWORDS: Forest industry. Waste Management. Waste wood.

\section{INTRODUÇÃO}

A indústria de base florestal e a indústria mineral podem ser consideradas como base da economia mundial, pois seus produtos, tanto primários quanto secundários, são usados como matéria-prima para outros setores econômicos como a construção civil, automobilística, naval, entre outras. Aquela indústria, no contexto nacional, é uma grande geradora de renda, tributos, divisas, empregos (NUNES et al., 2012).

Esse setor apresenta vários produtos resultantes da cadeia produtiva como: postes, madeira serrada, lâminas de madeira, painéis colados, compensados, aglomerados, chapas duras de fibra, chapas de fibras de média densidade, celulose e papel, além de energia e móveis (MINILLO, 2017). No Brasil, por causa da riqueza florestal, este setor da indústria se destaca. Essa riqueza está presente, principalmente, na floresta Amazônia que recobre aproximadamente $61 \%$ do território nacional e apresenta mais de $90 \%$ da produção florestal de áreas naturais do Brasil (RIVERO et al., 2011).

$\mathrm{Na}$ Região Amazônica, são extraídos, aproximadamente, 14 milhões de metros cúbicos de madeira em tora, sendo grande parte dessa extração feita de forma ilegal. A atividade da indústria madeireira na região Amazônia é muito intensa, estudos mostram que existem mais de duas mil indústrias que realizam o processamento industrial da madeira, empregando cerca de 66 mil trabalhadores apenas de forma direta e com uma receita bruta de 2,5 bilhões de dólares (FILGUEIRAS et al. 2018).

Muitas dessas indústrias de base florestal apresentam maquinário obsoleto, com isso, geram grande quantidade de resíduos de madeira. Esse resíduo, na maioria das vezes, não é aproveitado, causando problemas operacionais na própria indústria. Essa problemática não está restrita a indústria (local do empreendimento), pois os resíduos madeireiros são gerados em toda cadeia produtiva, mas o processamento primário é a etapa que mais contribui para a geração do mesmo (MINILLO, 2017).

Aspecto importante é que esse resíduo não é tóxico e pode ser classificado como sólidos e não inertes. Porém, o principal problema é a quantidade de resíduo 
que é gerado e a falta de destinação racional. Algumas empresas do setor madeireiro não se preocupam com a questão ambiental e econômica de armazenar, transportar e destinar o resíduo de maneira correta, podendo estes ser tornar passivos ambientais (RAMOS et al., 2016).

Imperiosamente, esse desperdício contribui para o aumento da exploração da floresta, que por sua vez, intensifica a crise ambiental que denota uma perspectiva de um futuro colapso ambiental provocada pelo aumento da população e consumo (ACSELRAD, 2004).

Devido a essas problemáticas, em 2010 foi publicada a Lei $\mathrm{n}^{0}$ 12.305/10, que instituiu a Política Nacional de Resíduos Sólidos (BRASIL, 2010). Essa política contém instrumentos importantes que visam o gerenciamento integrado e racional do resíduo. Ressalta-se que a presente política impõe que toda indústria que gere resíduo tem por obrigação elaborar um plano de gerenciamento de resíduos sólidos com o objetivo de amenizar a problemática que o envolve.

Não menos importantes são os problemas de saúde pública que podem ser ocasionados pela queima, como os problemas respiratórios (FARIAS et al. 2016). Ademais, o resíduo, em contato com substâncias tóxicas, pode contaminar os corpos d'água e o solo e também gerar riscos a saúde pública. Por isso, a reciclagem é uma prática de gerenciamento que deve ser feita por todas as empresas que os geram.

O aproveitamento do resíduo é a forma mais racional de diminuir o problema gerado, mas para isso, é preciso uma adequação no processo produtivo, com o uso de aspersores, coletores e um local de armazenamento correto, deixando o resíduo o menos úmido possível (RAMOS et al. 2017). Diante do exposto, percebe-se a importância da atividade de base florestal em um contexto socioeconômico. Porém, essa atividade tem gerado problemas socioambientais, principalmente, devido à grande quantidade de resíduos madeireiros gerados e a falta de destinação correta destes. Com isso, objetivou-se descrever o gerenciamento dos resíduos sólidos da indústria de base florestal na Região Metropolitana de Belém-PA.

\section{MATERIAL E MÉTODOS}

A área de estudo foi a Região Metropolitana de Belém do Pará-PA (Figura 1) localiza-se entre as coordenadas $01^{\circ} 23^{\prime} .6$ Sul e $048^{\circ} 29^{\prime} .5$. Apresenta clima classificado como Af segundo Köppen, com temperatura média anual de $26^{\circ} \mathrm{C}$, com UR de $90 \%$, o índice pluviométrico está entre $2.300 \mathrm{~mm}$ a $3.000 \mathrm{~mm}$ por ano.

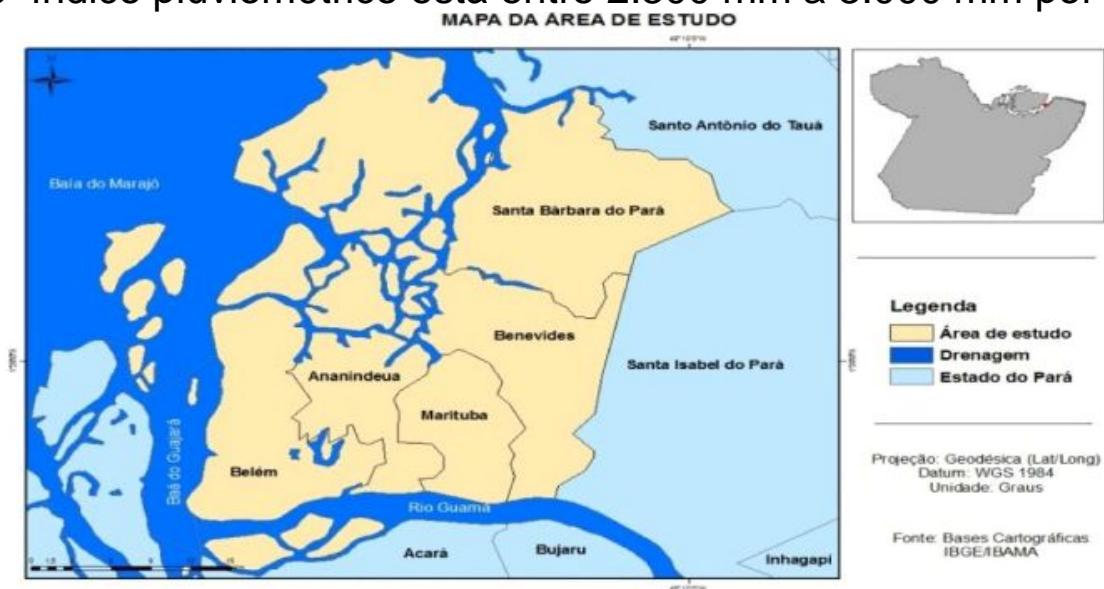

FIGURA 1- Mapa da Região Metropolitana de Belém

FONTE: Base cartográfica IBGE (2010) 
O presente trabalho se classifica como um estudo descritivo, observacional, aplicado e tem caráter de pesquisa exploratória, que visa proporcionar maior familiaridade com o problema, que neste caso é o resíduo da indústria madeireira, com vistas a torná-lo explícito (PRODANOV; FREITAS, 2016).

Para a obtenção do número de empresas do setor de base florestal e a localização, realizou-se um levantamento junto à Secretária Estadual do Meio Ambiente Sustentabilidade (SEMAS) e a Associação das Indústrias Exportadoras de Madeira do Estado do Pará (AIMEX), no período de novembro de 2014 a fevereiro de 2015.

Através do cruzamento dos dados da SEMAS e da AIMEX foi obtida uma população de 120 empresas potencialmente geradoras de resíduos de madeira. Essas empresas apresentam como ramo a serraria com desdobro de madeira, a serraria sem desdobro de madeira e movelarias.

Pela dificuldade de entrar em contato com as empresas devido a fatores como a inexistência de contato telefônico ou de email, endereços incompletos ou errados e recusa por parte dos empreendimentos em participar da pesquisa foi escolhida a técnica de amostragem não-probabilística por conveniência, na qual são selecionados os membros da população mais acessíveis. Dessa maneira, das 120 empresas, foram visitados 31 empreendimentos, todas localizadas na Região Metropolitana de Belém, no período de maio a julho de 2015.

Os dados foram coletados através de entrevista semi-estruturada na qual são conjugadas perguntas abertas e fechadas que poderiam ser atualizadas, dependendo da necessidade, ao longo da pesquisa. As perguntas foram feitas aos gerentes, diretores e responsáveis técnicos (engenheiro florestal) pelo processo produtivo das empresas. Além disso, visitas in loco e registro fotográfico da área de disposição, armazenamento e gerenciamento de resíduos foram feitas. A análise dos dados foi feita através da estatística descritiva.

\section{RESULTADOS E DISCUSSÃO}

Após as etapas iniciais de gerenciamento do resíduo nas empresas, estes são destinados de três formas, quais sejam: doação, venda (destinação fora da empresa) e logística reversa interna (destinação dentro da empresa). A doação é feita de maneira simples sem documentação com o objetivo de dar uma destinação rápida ao resíduo. A venda é a que, a empresa por contrato, vende o resíduo para terceiros com a emissão de nota fiscal/recibo. A logística reversa interna é feita na empresa e consiste em retornar com o resíduo para o sistema produtivo ou na forma de insumo ou de matéria-prima.

Ressalta-se que, a maioria das empresas realiza mais de uma forma de destinar esse resíduo. Algumas empresas vendem e doam, vendem e fazem a logística reversa interna e etc. Neste estudo, verificou-se que os resíduos são vendidos e doados para diferentes locais onde são aproveitados de diferentes formas. Assim, para Ramos et al., (2016) os resíduos podem ser utilizados de várias maneiras, a depender da viabilidade econômica e ambiental e a estrutura do local de geração destes, bem como a quantidade gerada .Dessa maneira, das 31 empresas, 25 vendem os seus resíduos. Esses resíduos são vendidos para outras empresas do setor madeireiro, para cerâmicas, olarias e granjas (Figura 2). 


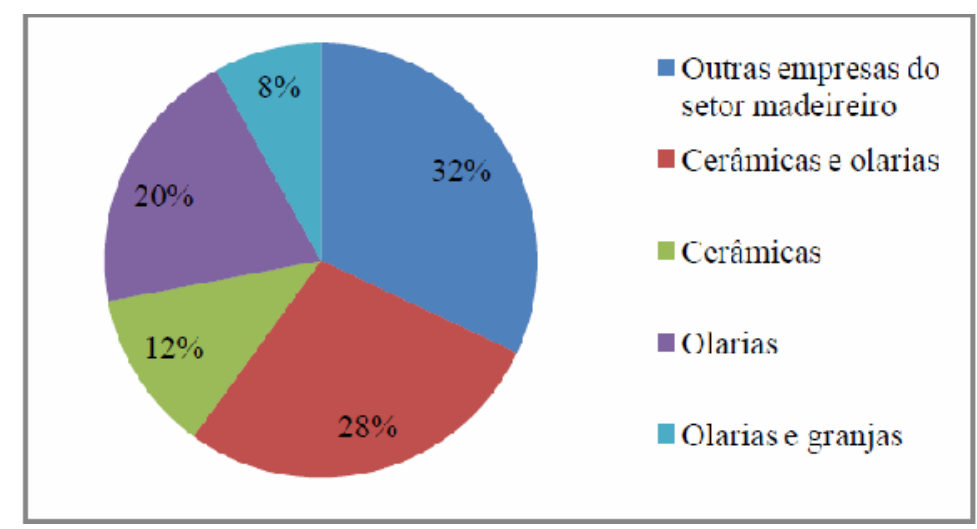

FIGURA 2- Destino do resíduo da indústria de base florestal que é vendido

Os resultados mostram que o principal destino do resíduo vendido é para outras empresas e com menor representação, o aproveitamento em olarias e granjas. Neste sentido, o aproveitamento dos resíduos na forração para criação de frangos já é um uso potencial, sendo doado e vendido pelos donos das marcenarias (GONDIM, 2017).

Dentro desses locais, que compram o resíduo, este é aproveitado, através do processo de reciclagem, de duas formas específicas, quais sejam: co-geração de energia em outras empresas madeireiras ou em fornos, nas cerâmicas e olarias; além disso, são aproveitados na avicultura como cama de aviário em granjas da Região. Entretanto, não foi estimado o montante $\mathrm{em}^{3}$ de resíduo que é usado como biomassa para combustão e como cama de aviário. Ressalta-se que cada tipo de resíduo tem um comprador diferente.

No que diz respeito a forma de destinação baseada na doação, das 31 empresas visitadas, 19 doam resíduos. Esses são doados, basicamente para panificadoras, granjas, comunidade, olarias e cerâmicas, nenhuma empresa doa para mais de um local.

Os resíduos madeireiros são doados principalmente para a comunidade e com menor representatividade, para olarias e cerâmicas (FIGURA 3). Dentro desses diferentes locais, o resíduo é aproveitado de forma similar com a qual é feita a venda.

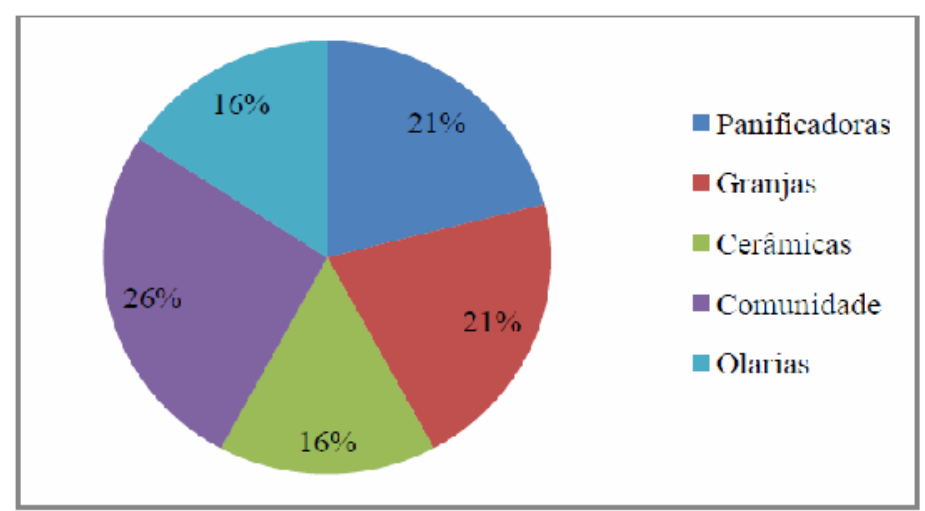

FIGURA 3- Destino do resíduo da indústria de base florestal que é doado

Assim, o aproveitamento de resíduos pode gerar receitas através de agregação de valor com a reciclagem ou a reutilização de forma racional (RAMOS et al., 2016). Porém, observou-se que há desconhecimento de muitas empresas AGRARIAN ACADEMY, Centro Científico Conhecer - Goiânia, v.5, n.9; p. 3622018 
sobre o que realmente é feito com o resíduo doado, pois muitas relataram que, por não haver um contrato e nem a necessidade de emissão de nota fiscal, não se preocupam em conhecer o real aproveitamento desse resíduo. Isso vai ao encontro com a Política Nacional de Resíduos sólidos, que enfatiza que a responsabilidade do resíduo é de quem o gerou (BRASIL, 2010), sendo este pressuposto legal não cumprido pelas empresas.

Ressalta-se que essa forma (doação) de destinar o resíduo não traz ganhos econômicos para as empresas, colaborando apenas para a redução do resíduo em na área de produção. Por outro lado, a doação de resíduos de madeira gera ganhos aos avicultores, que deixam de comprar insumos para a produção, bem como para a produção de artefatos de madeira (FIGUEREDO et al., 2013).

A logística reversa interna, que é feita na própria empresa geradora do resíduo, foi verificada em 11 indústrias, esses resíduos são aproveitados através do processo de reciclagem para a fabricação de briquete, pequenos objetos de madeira (POM), os quais são vendidos como subprodutos do processo produtivo, também são utilizados em caldeiras ou fornos para a geração de energia térmica ou elétrica (co-geração de energia) (Figuras 4).Destaca-se que essa forma de destinar o resíduo é a que gera mais ganhos econômicos, sociais e ambientais, pois há uma valorização do resíduo, com o aproveitamento deste para a fabricação de outros produtos, o que gera emprego, além de diminuir a pressão sobre a floresta.

(A)

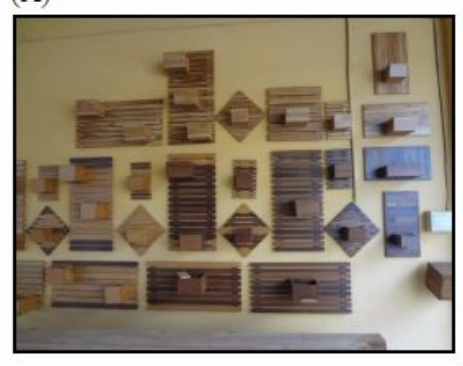

(C)

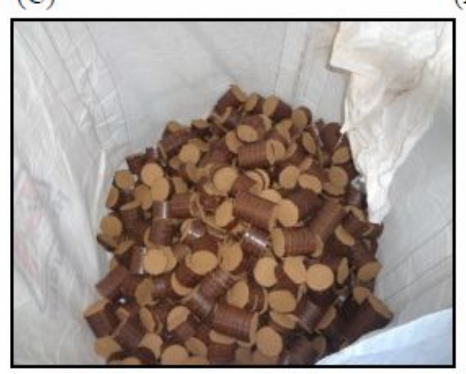

(D)
(B)
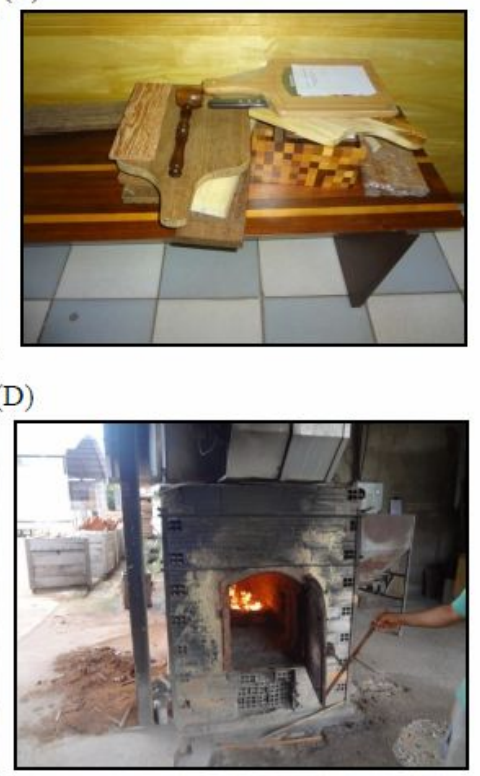

FIGURA 4. Formas de aproveitamento do resíduo dentro da empresa por meio da reciclagem do resíduo. (A) produção de pequenos objetos de madeira (POM) ou produtos com maior valor agregado de madeira (PMVA) para decoração; (B) produção de pequenos objetos de madeira (POM) como utensílios domésticos e brinquedos;

(C) Briquetes embalados para venda a outras empresas;

(D) caldeira sendo abastecida por resíduos gerados na própria empresa e gerando energia térmica para secagem da madeira na empresa.

A principal forma de retorno do resíduo ao processo produtivo através do aproveitamento ou como matéria-prima secundária ou como insumo no processo 
produtivo na empresa é a Co-geração de energia. Ressalta-se que é realizada pelos empreendimentos pesquisados mais de uma forma de aproveitamento desse resíduo (FIGURA 5).

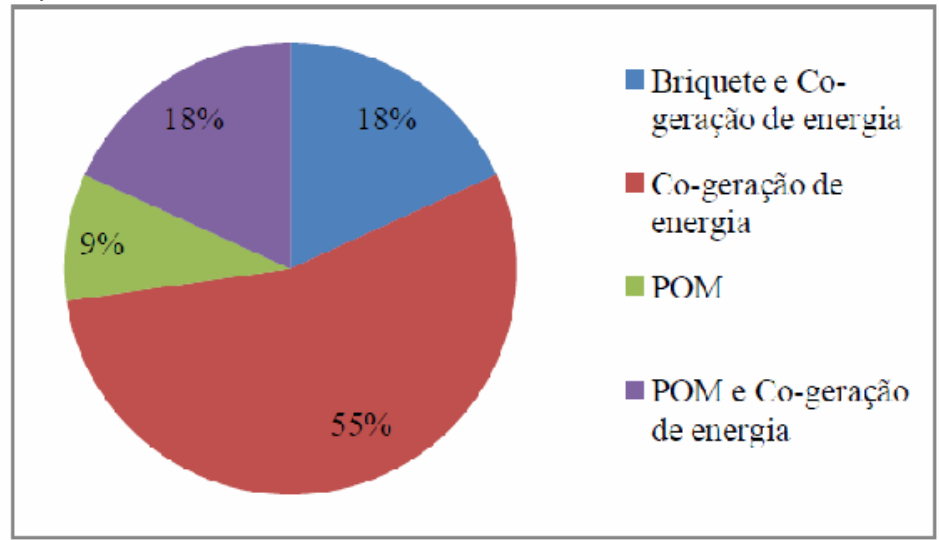

FIGURA 5- Diferentes tipos de aproveitamento, através da reciclagem, realizado dentro das empresas de base florestal.

Cheah Chee Ban (2010), coloca que a indústria madeireira usa significativo volume dos resíduos de madeira originados nos processos para a geração de energia. Sendo os resíduos de madeira, os combustíveis preferidos para fornos de biomassa, visto que a incineração produz cinza relativamente menos volátil e outros materiais residuais em comparação com outras biomassas.

Além desse tipo de aproveitamento, os resíduos são usados, em menor quantidade para a fabricação de briquete ou para a fabricação de pequenos objetos de madeira (POM). Esses são vendidos para grandes lojas varejistas da região. Já os briquetes são comercializados para empresas de processamento secundário de madeira e para uma empresa de cosméticos em Mosqueiro.

A fabricação do briquete usando o resíduo de madeira é uma possível solução para o problema do gerenciamento de resíduos e ainda para a questão energética. Dentro dessa ótica, corrobora-se com Paixão et al. (2014), os quais afirmam que apenas uma parcela do volume de resíduos gerados têm algum aproveitamento econômico, social e/ou ambiental. Assim uma postura pró-ativa das empresas desse setor, que gere desenvolvimento sustentável, advém da implementação de uma série de estratégias que têm como objetivo a redução e valorização dos resíduos e, por conseguinte, a eliminação da necessidade de disposição final e os impactos ambientais negativos da produção, indo muito além das exigências da legislação (RAMOS et al. 2017).

Separando as empresas que realizam o processamento primário e as que realizam o processamento secundário juntamente com as movelarias, observa-se que esses segmentos apresentam características de destinação dentro e fora da empresa bem distintas (Figura 6). 


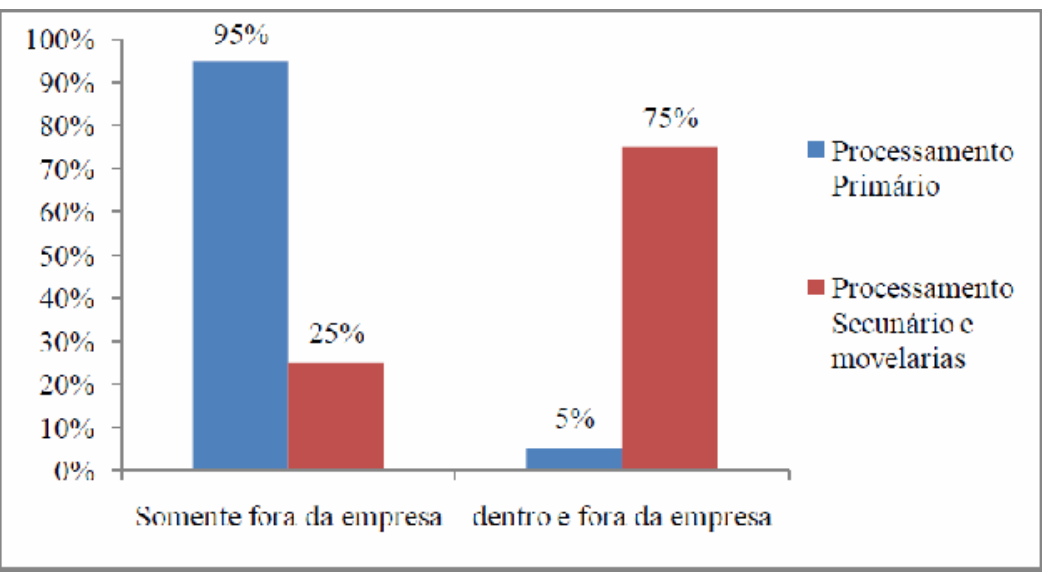

FIGURA 6- Destino do resíduo dentro e fora das empresas que realizam o processamento secundário juntamente com as movelarias e as que realizam o processamento primário.

A grande maioria das empresas $(75 \%)$ que realizam o processamento secundário e de móveis destina o resíduo dentro da empresa, isso é explicado, pois os seus processos geram menos resíduo de madeira, o que facilita o retorno ao processo produtivo na própria empresa. Além disso, essas empresas apresentam maior preocupação em aproveitar economicamente os resíduos. Por outro lado, as empresas que realizam o processamento primário destinam os resíduos de forma expressiva fora da empresa, isso é devido à baixa tecnologia existente nessas empresas para aproveitar o resíduo e principalmente a grande quantidade de resíduos gerados, inviabilizando, dessa forma, o aproveitamento dentro da empresa.

Destaca-se que, nenhum empreendimento destina $100 \%$ do resíduo através da logística reversa interna (aproveitamento dentro da empresa), até as que realizam o processamento secundário e as movelarias destinam uma parte dos resíduos fora da empresa ou por meio da venda ou por doação. Entretanto, verificou-se que na maioria dos empreendimentos de base florestal, o gerenciamento do resíduo sólido é feito de maneira incipiente, principalmente, nas empresas que realizam o processamento primário da madeira, ou seja, os resíduos madeireiros não são destinados adequadamente. Ressalta-se que as etapas de triagem e armazenamento do resíduo são fundamentais para que este seja destinado de forma ambientalmente adequada. Ademais, cada espécie florestal gera um tipo de resíduo com características de aproveitamento diferente, mas isso não foi verificado no presente estudo.

\section{CONCLUSÃO}

Com a falta de um plano de gerenciamento de resíduos sólidos padrão na maioria das empresas, verificou-se que há diversas formas de destinar o resíduo gerado. Sendo a logística reversa a que gera mais ganhos econômicos a empresa, bem como a venda, porém, com ganhos menores. No caso da doação, a problemática que é inerente a esta pratica é, pois, que as empresas não apresentam o controle nem o conhecimento do real destino desses resíduos, podendo, incorrerem em responsabilidade solidária.

Assim, verificou-se que os resíduos ainda são um problema, com o gerenciamento sendo feito de forma incorreta em muitos empreendimentos. Porém, iniciativas racionais, que tornam o resíduo um subproduto da cadeia produtiva 
podem gerar ganhos socioambientais e econômicos para a empresa e a comunidade circunvizinha.

\section{REFERÊNCIAS}

NUNES, P. A.; DE MELO, C. O.; TEIXEIRA, D. A participação do setor madeireiro na economia das microrregiões geográficas do Paraná - 2009. Revista Brasileira de Agropecuária Sustentável, RBAS, v.2, n.1, p.8-20, Jul. 2012. Disponível em $<$ http://dx.doi.org/10.21206/rbas.v2i1.53. Acesso em out. de 2015.

MINILLO, L. Q. Aproveitamento de resíduo das indústrias de celulose e sucroalcoleira para produção de painéis aglomerados. 2017. Disponível em https://repositorio.unesp.br/handle/11449/150031, acesso em 15/07/2018.

RIVERO, S.; ALMEIDA, O.; DO ROSÁRIO, L. F.; RODRIGUES, L. F.; AROUCK, J. H. S.; FERNANDEZ, R. D. Instituições, gestão dos recursos naturais e o setor madeireiro no Estado do Pará. Amazônia: Ciência \& Desenvolvimento., Belém, v. 7, n. 13, jul./dez. 2011.

FILGUEIRAS, G. C., DE LIMA CAIRES, M. D. S., CARVALHO, A. C., ARAÚJO, A. C. D. S., DE CARVALHO, A. V. Desenvolvimento local sustentável através da produção concentrada de madeira em tora no Estado do Pará. Revista Agroecossistemas, v. 9, n. 2, p. 102-129, 2018.

ACSELRAD, $H$. As práticas espaciais e o campo dos conflitos ambientais. In: Acselrad, H. Conflitos ambientais no Brasil. Relume-Dumará, pp. 7-36, 2004

BRASIL. Lei no 12.305, de 2 de agosto de 2010. Dispõe sobre seus princípios, objetivos e instrumentos, bem como sobre as diretrizes relativas à gestão integrada e ao gerenciamento de resíduos sólidos, incluídos os perigosos, às responsabilidades dos geradores e do poder público e aos instrumentos econômicos aplicáveis. Diário Oficial [da] União, Brasília, DF, 03 agosto de 2010.

FARIAS, B. S. S., FRANÇA, A. C. S., AZEVEDO, P. S., SANTOS, D. M., VALPORTO, M. S., DE LOURDES MONTEIRO, K., ROCHA, L. T. C. Comparativo de impactos ambientais entre produtos provenientes da madeira para projetos de mobiliário. Blucher Design Proceedings, v. 2, n. 9, p. 4143-4154, 2016.

IBGE - Instituto Brasileiro de Geografia e estatística . Censo demográfico de 2010: educação e deslocamento.Disponível em: <http://www.cidades.ibge.gov.br/xtras/perfil.php?lang=\&codmun=150140\&search=par a|belem, 2010=>. Acesso em: 18 de jun. de 2014.

PRODANOV, C. C.; FREITAS, EC de. Metodologia do Trabalho Científico: Métodos e Técnicas da Pesquisa e do Trabalho Acadêmico Novo Hamburgo: Editora Feevale, v. 20, 2016.

GONDIM, G. V. Potencial de geração de energia a partir dos resíduos sólidos orgânicos e efluentes líquidos gerados em uma unidade agroindustrial, 2017.Disponível em ; https://repositorio.unesp.br/handle/11449/150973 , acesso em 15/7/2018. 
CHEAH CHEE BAN, M. R. The implementation of wood waste ash as a partial cement replacement material in the production of structural grade concrete and mortar: An overview. Elsevier / Resources, Conservation and Recycling, v.55, n.7, p. $669-685,2010$.

PAIXÃO, C. P. S., FERREIRA, E., STACHIW, R. Produção e destinação dos resíduos gerados em serrarias no município de Rolim de Moura - RO. Revista Brasileira de Ciências da Amazônia, v. 3, n. 1, p. 47-56, 2014.

RAMOS, W. F. RUIVO, M. D. L. P., CASTRO, R. M. D. S., PORRO, R., SOUSA, L. M. D., JARDIM, M. A. G. Análise da indústria madeireira na Amazônia: gestão, uso e armazenamento de resíduos. Revista Brasileira de Ciências Ambientais, São Paulo, n.43, p. 1-16, Jan/Mar. 2017.

RAMOS, W. F.; RUIVO, M. L. P.; SOUSA, L. M. Análise do aspecto produtivo das indústrias madeireiras de processamento primário da Região Metropolitana de Belém. Revista Enciclopédia Biosfera, Goiânia, v.13 n.24; p. 39-50, out/dez, 2016. 